\title{
$\mathrm{M}|\mathrm{R}| \mathrm{S}$
}

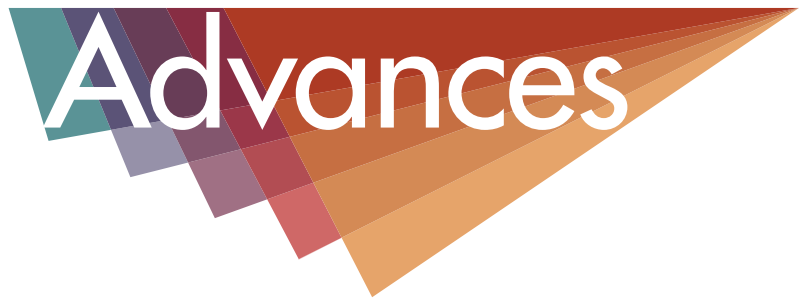

\section{Processing and Manufacturing}




\section{MRS Advances: Processing and Manufacturing}

\section{Associate Editor:}

Asa Barber, University of Portsmouth

\section{Principal Editors:}

Esperidiana Moura, USP-IPEN

Akira Mizuno, Toyohashi University of Technology

Rainer Hebert, University of Connecticut

Meyya Meyyappan, NASA

Mark Poliks, Binghamton University

\section{MRS Advances Editorial Board:}

Editor-in-Chief: David F. Bahr, Purdue University Asa Barber, University of Portsmouth,

United Kingdom

Meenakshi Dutt, Rutgers University

Elizabeth L. Fleischer, Materials Research Society
Marian Kennedy, Clemson University Marilyn L. Minus, Northeastern University

Roger J. Narayan, University of North Carolina/North Carolina State University Jeremy Theil, Mountain View Energy

Materials Research Society Editorial Office, Warrendale, PA:

Ellen W. Kracht, Publications Manager

Susan Dittrich, Journals Editorial Assistant
Kirby L. Morris, Journals Production Assistant Eileen M. Kiley, Director of Communications

\section{Disclaimer}

Authors of each article appearing in this Journal are solely responsible for all contents in their article(s) including accuracy of the facts, statements, and citing resources. Facts and opinions are solely the personal statements of the respective authors and do not necessarily represent the views of the editors, the Materials Research Society, or Cambridge University Press.

MRS Advances (EISSN: 2059-8521) is published by Cambridge University Press, One Liberty Plaza, Floor 20, New York, NY 10006 for the Materials Research Society.

Copyright (C) 2017, Materials Research Society. All rights reserved. No part of this publication may be reproduced, in any form or by any means, electronic, photocopying, or otherwise, without permission in writing from Cambridge University Press. Policies, request forms and contacts are available at: http://www.cambridge.org/rights/permissions/permission.htm. Permission to copy (for users in the USA) is available from Copyright Clearance Center at: http://www.copyright.com,

气 email: info@copyright.com.

\section{Purchasing Options:}

Premium Subscription- Premium Subscription includes current subscription and one year's lease access to the full MRS Online Proceedings Library Archive for \$7,219.00 / £4,888.00 / €6,647.00. SubscriptionฐS Subscription with perpetual access to the content subscribed to in a given year, including three years of back-file lease access to content from the MRS Online Proceedings Library Archive. The price for ऽ 2017 subscription is $\$ 3,019.00$ / £1,948.00 / €2,625.00. MRS Members-Access to MRS Advances à is available to all MRS members without charge.

\section{Contact Details:}

For all inquiries about pricing and access to MRS Advances, please get in touch via the following email addresses: online@cambridge.org (for the Americas); library.sales@cambridge.org (for UK, Europe, and rest of world).

\section{cambridge.org/adv}




\section{CONTENTS}

Low Cost Method for Generating Periodic Nanostructures by Interference Lithography Without the Use of an Anti-reflection

Coating. . . . . . . . . . . . . . . . . . . . . . . . . . . . . . . . . . . . . .

Omree Kapon, Merav Muallem, Alex Palatnik,

Hagit Aviv, and Yaakov R. Tischler

Silicon Stabilized Alumina Thin Films as Gas Permeation

Barriers Prepared by Spatial Atomic Layer Deposition . . . . . . . . .933

Sebastian Franke, Sebastian Beck,

Reinhard Caspary, Hans-Hermann Johannes,

Annemarie Pucci, and Wolfgang Kowalsky

Synthesis of $\mathrm{LiFePO}_{4}$ in an Open-air Environment . . . . . . . . . .939

Fei Gu, Kichang Jung, Taehoon Lim,

and Alfredo A. Martinez-Morales

Synthesis of $\mathrm{LiFePO}_{4}$ Using an Ionic Liquid/Water Composite

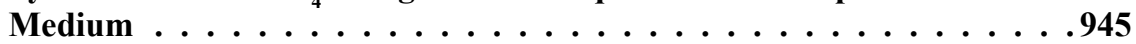

Rany Tith, Darren Kwee, Kichang Jung,

and Alfredo A. Martinez-Morales

Fabrication and Characterization of Nanofiber Enhanced

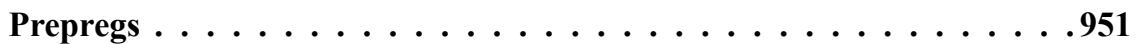

ABM Iftekharul Islam and Ajit D. Kelkar

Combination of Hot Forming with CRP and Rapid Cooling to

Obtain Enhanced Formability in Thermomechanical Treatment . . . . .957

Peter Birnbaum, Markus Baumann,

Andreas Kunke, Verena Kraeusel,

and Dirk Landgrebe

Macroscopic Characterization of Mechanical Properties in

Electric Current Treated Dry Drawn High Strength Wires . . . . . . . 963

Osamudiamen Omoigiade, Arunansu Haldar,

and Rongshan Qin 